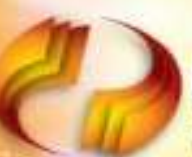 PRODUCIĀO ONLINE REVISTA CIENTIFICA ELETRÖNICA DE ENGENHARIA DE PRODUÇĀO ISSN 1676-190|
}

\section{MÉTODOS PARA A TOMADA DE DECISÃO EM PORTFÓLIO DE PRODUTOS: UM LEVANTAMENTO EM EMPRESAS DOS SETORES ELETRÔNICO, ÓPTICO E DE INFORMÁTICA}

\section{METHODS FOR DECISION MAKING IN PRODUCT PORTFOLIO: A SURVEY AT ELECTRONIC, OPTICAL AND COMPUTING COMPANIES}

\author{
Mila Gibran Silva* E-mail: gibran.mila@gmail.com \\ Juliene Navas Leoni* E-mail: juliene leoni@hotmail.com \\ Daniel Jugend* E-mail: daniel@feb.unesp.br \\ Sergio Luis da Silva** E-mail: sergiol@power.ufscar.br \\ Manoel Henrique Salgado*E-mail: henri@feb.unesp.br \\ *Universidade Estadual Paulista Júlio de Mesquita Filho (UNESP), Bauru, SP \\ **Universidade Federal de São Carlos (UFSCAR), São Carlos, SP
}

Resumo: A tomada de decisão em portfólio de produtos é aspecto relevante, não apenas para o bom desempenho do desenvolvimento de produtos, mas também para auxiliar no processo da estratégia de negócio. Este artigo possui o objetivo de apresentar e analisar os principais métodos para a tomada de decisão em portfólio de produtos adotados por grandes e médias empresas, que atuam no Brasil, nos setores eletrônicos, óptico e de informática. Foi realizada uma pesquisa do tipo survey em uma amostra de 40 empresas. Notou-se que grande parte dessas, especialmente as de médio porte, segue um padrão informal para a tomada de decisão em portfólio de produtos e, que são guiadas, sobretudo, pela percepção da alta administração. Dentre os métodos formais empregados, os financeiros, de pesquisa de mercado e de mapeamento são os mais presentes nos setores estudados.

Palavras-chave: Processo de desenvolvimento de produtos. Gestão de Portfólio de Produtos. Métodos para a tomada de decisão. Pesquisa tipo survey. Empresas dos setores eletrônicos, óptico e de informática.

Abstract: Decision making in product portfolio is a relevant aspect, not only to the good performance of product development, but also to support in the process of business strategy. This article has the objective to present and analyze the main methods for decision making in product portfolio used by large and medium enterprises that operate in Brazil, in electronic, optical and computer sectors. A survey research was conducted in a sample of 40 companies. It was noted, that most of these companies, especially the middle sized companies, followed an informal pattern for decision-making in product portfolio, which is guided, mainly, by the perception of senior management. Among the employed formal methods, financial, market research and mapping methods are the most present in the surveyed sectors.

Keywords: Process of Product Development. Product Portfolio Management. Methods for Decision Making. Survey research. Electronic, optical and computing companies. 


\section{INTRODUÇÃO}

O tema gestão do portfólio de produtos vem recebendo destaque em trabalhos das áreas de desenvolvimento novos de produtos e gestão da inovação (EGGERS, 2012; HAUSER et al., 2006). Este destaque ocorre, pois a linha atual de produtos somada aos seus projetos de produtos futuros, isto é, o portfólio de produtos pode ao mesmo tempo, favorecer a concretização da estratégia planejada para o negócio e contribuir para o melhor desempenho dos processos de inovação e de desenvolvimento de produtos (PDP).

Oliveira e Rozenfeld (2010) definem a gestão de portfólio de produtos como um processo dinâmico, no qual os projetos de novos produtos são sistematicamente revisados e atualizados. Cooper et al. (1999) apontam que a gestão de portfólio de produtos possui caráter estratégico, pois, as suas deliberações são responsáveis por determinar não apenas os projetos de novos produtos, mas, também, revisões, atualizações e até mesmo decisões de descontinuidade sobre os produtos atualmente produzidos e comercializados,

No entanto, a gestão de portfólio de produtos é entendida atividade complexa no que se refere à sua tomada de decisão (KESTER et al., 2011; KILLEN; KJAER, 2013). Afinal, faz parte da etapa de pré-desenvolvimento do PDP, consideradas por alguns autores como pertencentes ao fuzzy front end (CUNHA et al., 2010; MCNALLY et al., 2013),quando normalmente ainda existe pouco conhecimento do resultado a ser alcançado, uma vez que se está pensando nas características que um produto deve ter final com muita antecipação em relação ao momento em que o produto será efetivamente lançado (MCNALLY et al., 2009). Dificulta-se, dessa forma, a previsão de todas as atividades e, por consequência, o resultado final desse processo.

Devido a este caráter estratégico e complexo, diversos métodos de gestão são recomendados para auxiliar as empresas para a melhor qualidade na tomada de decisão em portfólio de produtos (CHENG, 2003; COULON et al., 2009). Dentre esses métodos, pode-se destacar os financeiros, de pontuação e priorização, a pesquisa de mercado, checklists, mapas, gráficos e os diagramas (CASTRO; CARVALHO, 2010; COOPER et al., 1999; KESTER et al. 2011; JUGEND; SILVA, 2013).

Revista Produção Online, Florianópolis, SC, v.14, n. 3, p. 1151-1170, jul./set. 2014. 
Estudos anteriores realizados em empresas de base tecnológica que atuam no Brasil identificaram que as atividades de pré-desenvolvimento do PDP, o que inclui a gestão e a tomada de decisão em portfólio de produtos, estão elencados entre os principais fatores críticos de sucesso associados a este processo (TOLEDO et al., 2008; JUGEND; SILVA, 2010). Este artigo tem o objetivo de apresentar e analisar os principais métodos que médias e grandes empresas dos setores eletrônicos, óptico e de informática adotam para a tomada de decisão em portfólio de produtos. Para isso, foi realizada uma pesquisa tipo survey, a qual coletou dados em 40 empresas desses setores espalhadas pelo país.

Escolheu-se realizar a pesquisa em empresas desses setores, pois de acordo com a Pesquisa de Inovação realizada pelo Instituto Brasileiro de Geografia e Estatística (IBGE, 2008), os setores eletrônicos, óptico e de informática se destacaram entre os que apresentaram às maiores taxas de inovação no Brasil. A opção por empresas de médio e grande porte ocorreu, pois, de acordo com Vermulum e Erber (2002) são as que possuem melhores condições para realizar sistemáticas atividades de inovação tecnológica ao longo do PDP, já que, em muitos casos, são as que detêm os recursos necessários para isso, como por exemplo: instalações, máquinas, mão de obra adequada, investimento em P\&D e competências específicas em engenharia, produção, marketing e P\&D.

O artigo inicialmente apresenta breve revisão teórica sobre gestão de portfólio de produtos. Em seguida, aborda-se o método de pesquisa empregado e, posteriormente, apresentam-se e discutem-se os resultados empíricos obtidos. Por fim, são delineadas as considerações finais.

\section{GESTÃO DE PORTFÓLIO DE PRODUTOS}

As empresas que possuem atividades de desenvolvimento de novos produtos, normalmente, se defrontam com o desafio de gerenciar o portfólio de produtos. É consenso entre diversas publicações que a gestão do portfólio de produtos deve cumprir fundamentalmente três objetivos básicos ao longo do PDP, são eles: alinhamento entre o portfólio de produtos e a estratégia de negócio, balanceamento e a maximização de valor (COOPER, et al. 1999; CAUCHICK 
MIGUEL, 2008; KILLEN et al., 2008; KESTER et al., 2009; CASTRO; CARVALHO, 2010; KESTER et al., 2011; MCNALLY et al., 2013).

A finalidade do alinhamento do portfólio de produtos consiste em traduzir e alinhar a estratégia da empresa em um conjunto produtos, de forma a se considerar as linhas de produtos atuais ou futuras que serão responsáveis pela viabilização da estratégia de negócio, especialmente no que se diz respeito aos objetivos de inovação de produtos (BARROS et al., 2010; CASTRO; CARVALHO, 2010; MCNALLY et al., 2013). O balanceamento está relacionado ao mix de projetos de produtos (EGGERS, 2012; MIKKOLA, 2001) e contempla questões como a avaliação do grau de inovação de cada um dos produtos que compõem o portfólio, riscos e recompensas previstos com o desenvolvimento desses projetos, segmentos de mercado que cada produto pretende atingir e prazos de execução (projetos de curto, médio e longo prazo). A maximização de valor do portfólio visa, basicamente, otimizar a relação entre recursos utilizados e retornos previstos com os projetos de produtos (MCNALLY et al., 2009; KESTER et al., 2009).

Pesquisas anteriores levantaram dificuldades que as empresas normalmente se defrontam para o cumprimento destes objetivos, e para o bom desempenho da gestão do portfólio de produtos. Alguns trabalhos mencionam que por determinar produtos que uma organização irá competir, as decisões de portfólio estão associadas aos momentos críticos de pré-desenvolvimento do PDP, que tem como característica central a grande quantidade de ideias de projetos somada à elevada incerteza de resultados (KOEN et al., 2002; MCNALLY et al., 2009; CUNHA et al., 2010).

Cooper et al. (1999) e Ernst (2002), sugerem que uma das principais causas de insucesso no PDP ocorre, principalmente, em virtude de falhas gerenciais presentes nas atividades de planejamento do portfólio de produtos. Segundo esses autores, muitas empresas falham em nível estratégico, pois, geralmente, focam em projetos individuais e não os integram aos outros projetos e ao planejamento estratégico.

Archer e Ghasenzadeh (1999), Cooper et al. (2000) e Castro e Carvalho (2010) destacaram que a tomada de decisão acerca do portfólio de produtos deve ser gerenciada de maneira cuidadosa. De acordo com esses autores, se por um lado, as empresas de características mais inovadoras normalmente possuem muitos

Revista Produção Online, Florianópolis, SC, v.14, n. 3, p. 1151-1170, jul./set. 2014. 
projetos de novos produtos, mas, por outro, há limitação de tempo, recursos financeiros e humanos. Além disso, conforme observado por Kavadias e Chao (2007), muitas empresas também possuem dificuldades em priorizar os seus projetos de novos produtos.

Os trabalhos de Cooper et al. (1999), Coulon et al. (206), Kahn et al. (2006), McNally et al. (2009), Killen et al. (2008) identificaram que as empresas que possuem melhor desempenho em portfólio de produtos são justamente aquelas que adotam mecanismos formais e sistematizados para conduzir essas atividades e que contam com métodos específicos de gestão para auxílio para a tomada de decisão sobre quais produtos devem ser mantidos, desenvolvidos e descontinuados. Dentre estes métodos, se destacam os financeiros, pesquisa de mercado, checklist, de pontuação, de ranqueamento, mapas, gráficos e diagramas (ARCHER; GHASEMZADEH, 1999; CASTRO; CARVALHO, 2010; COOPER, et al., 1999; KILLEN et al., 2008; MIKKOLA, 2001; PEDROSO et al., 2012; OH et al., 2012; KILLEN; KJAER, 2013).

Os métodos financeiros se sobressaem para o alcance do objetivo de maximização do valor de portfólio (KAVADIAS; CHAO, 2007; Oliveira e Rozenfeld, 2010). Os seguintes mecanismos financeiros de avaliação costumam ser citados como adequados para análise de projetos de produtos: valor presente líquido, valor comercial esperado, taxa interna de retorno, ponto de equilíbrio, payback e retorno sobre investimento (COOPER et al., 2000; KAVADIAS; CHAO, 2007). Alguns estudos também sugerem a aplicação da teoria das opções reais para a tomada de decisão em portfólio de produtos em empresas que atuam em ambientes mais dinâmicos (SANTOS; PAMPLONA, 2005; MATHEWS, 2011), como as de base tecnológica por exemplo.

Souder et al. (1997) e Kester et al. (2011) destacam a importância das atividades de marketing, especialmente os trabalhos de pesquisa de mercado e o envolvimento do pessoal de P\&D e engenharia em atividades de marketing, como meio para a obtenção e análise de informações sobre as necessidades de clientes e da atuação da concorrência, o que pode subsidiar e melhorar a qualidade da tomada de decisão em portfólio de produtos.

Os modelos de pontuação sugerem que os projetos de produtos sejam ranqueados e priorizados de acordo com a média esperada de seu desempenho, e, 
conforme respectivos graus de alinhamento com a estratégia de negócio (COOPER et al., 2000; OLIVEIRA; ROZENFELD, 2010). Esses modelos requerem o estabelecimento prévio de critérios a serem julgados. Posteriormente, atribuem-se notas a cada um destes critérios. Esses mesmos critérios, podem ser analisados mediante o método checklist, o qual se propõe a observar se o projeto de produto atende determinados critérios de mercado, de desempenho e técnicos previamente considerados como relevantes pela empresa (CHRISTIANSEN; VARNES, 2008; MOREIRA; CHENG, 2010).

Trabalhos como o de Phaal et al. (2008) e Oliveira et al. (2012) vem chamando atenção para a aplicação dos mapas de produtos, como meio para o cumprimento dos objetivos balanceamento e alinhamento estratégico. A construção desses mapas pode ser realizada mediante a aplicação do método technology roadmap, como proposto por Phaal et al. (2001). A adoção de gráficos e diagramas, como os de bolhas e a matriz BCG também são recomendados como mecanismos úteis para simultaneamente se analisar a relação entre portfólio de produtos com a estratégia da empresa e o balanceamento (MIKKOLA, 2001; KAVADIAS; CHAO, 2007; KILLEN; KJAER, 2013).

Há certo consenso na literatura de que as decisões em portfólio de produtos e a aplicação desses métodos sejam realizados a partir de análises de equipes multifuncionais (SOUDER et al., 1997; CAUCHICK MIGUEL, 2008; KESTER et al., 2011). Esta equipe pode verificar inicialmente se as ideias de projetos de produtos serão mantidas, "congeladas" ou interrompidas. Para isso, por meio dos mecanismos financeiros e de pontuação citados, cada projeto pode ser avaliado individualmente. Tem-se então uma lista de projetos de produtos que serão interrompidos e aqueles que serão encaminhados e priorizados para o desenvolvimento propriamente dito, passa-se então ao planejamento individual de cada projeto de produto (COOPER et al., 2000; JUGEND; SILVA, 2013).

O quadro 1 apresenta síntese dos métodos de gestão de portfólio de produtos discutidos nesta revisão bibliográfica. 
Quadro 1- Síntese dos métodos aplicados para a tomada de decisão em portfólio de produtos

\begin{tabular}{|c|l|}
\hline Métodos & \multicolumn{1}{|c|}{ Síntese de aplicação em portfólio de produtos } \\
\hline Financeiros & $\begin{array}{l}\text { Utilização de métodos para análise financeira e econômica para a avaliação dos } \\
\text { projetos de produtos (por exemplo: payback, valor presente líquido e taxa interna } \\
\text { de retorno). A teoria opções reais também tem sido consideradas para a análise } \\
\text { e tomada de decisão em projetos que contenham maior grau de inovação } \\
\text { tecnológica. }\end{array}$ \\
\hline $\begin{array}{c}\text { Pesquisa de } \\
\text { Mercado }\end{array}$ & $\begin{array}{l}\text { Utilização sistemática de informações de mercado para apoiar a tomada de } \\
\text { decisão em portfólio de produtos. }\end{array}$ \\
\hline $\begin{array}{c}\text { Pontuação e } \\
\text { Ranqueamento }\end{array}$ & $\begin{array}{l}\text { Utilização de mecanismos para atribuição de notas/pontuação e posterior } \\
\text { priorização dos projetos de produtos. }\end{array}$ \\
\hline $\begin{array}{c}\text { Mapas, Gráficos e } \\
\text { Diagramas }\end{array}$ & $\begin{array}{l}\text { Representação visual do portfólio de produtos atual e futuro de produtos e } \\
\text { tecnologias. Auxilio para as tomadas de decisões e alocações de recursos ao } \\
\text { longo do ciclo de vida do produto. }\end{array}$ \\
\hline Checklist & $\begin{array}{l}\text { Aplicação de lista de critérios previamente definidos que visam determinar se há } \\
\text { mérito e/ou o valor do projeto de produto que esta em avaliação. }\end{array}$ \\
\hline
\end{tabular}

O próximo tópico deste artigo apresenta o método de pesquisa empregado. Em seguida os resultados são apresentados e discutidos.

\section{MÉTODO DE PESQUISA}

Tendo em vista que este artigo possui como objetivo apresentar e analisar os principais métodos que médias e grandes empresas dos setores eletrônicos, óptico e de informática adotam para a tomada de decisão em portfólio de produtos, foi realizada uma pesquisa do tipo survey, a qual é recomendada por Miguel e Ho (2010) como a mais indicada quando se deseja obter um panorama descrtivo de dado fenômeno, sendo também apontada como uma das mais adequadas quando se deseja fazer pesquisas quantitativas na área de gestão de operações (Forza, 2002).

Desenvolveu-se um questionário estruturado para a operacionalização desta pesquisa, que visou identificar os principais métodos de gestão utilizados para a tomada de decisão em portfólio de produtos. Para a compreensão do escopo dos objetivos desta pesquisa, no início do questionário foi solicitado que o respondente compreendesse a gestão de portfólio de produtos como aquelas atividades responsáveis por planejar e escolher os projetos de novos produtos a serem Revista Produção Online, Florianópolis, SC, v.14, n. 3, p. 1151-1170, jul./set. 2014. 
desenvolvidos pela empresa, as revisões e atualizações dos produtos atualmente produzidos e comercializados, e a retirada dos produtos do mercado (decisões de descontinuidade).

Como já justificado na introdução do artigo, para participar desta pesquisa foram escolhidas empresas que desenvolvem produtos e pertencentes aos setores eletrônicos, ópticos, e equipamentos de informática. Com a finalidade de identificar a população de empresas nos setores escolhidos, os pesquisadores investigaram o banco de dados da Associação Brasileira da Indústria Elétrica e Eletrônica (ABINEE) e, também, o banco de dados de empresas cadastradas no Instituto Nacional de Metrologia, Qualidade e Tecnologia (INMETRO), pertencentes aos setores eletrônico, óptico e de equipamentos de informática. Para definir média e grande empresa, utilizou-se o critério do SEBRAE (Serviço Brasileiro de Apoio às Micro e Pequenas Empresas) e do IBGE. De acordo com esses órgãos, na indústria, são classificadas como médias empresas aquelas que possuem de 100 a 499 funcionários e como grandes, aquelas que possuem acima de 500 funcionários.

Para gerenciar o envio dos questionários, foi criado um site com a finalidade de hospedar o instrumento de pesquisa. Nesse site foi possível cadastrar toda a população de empresas e enviar o link contendo o questionário a cada uma delas. Ao receber o link, o respondente era direcionado ao questionário hospedado no ambiente virtual da pesquisa. O cargo dos respondentes foi composto, em sua maioria, pelos diretores, gerentes de P\&D, gerentes de engenharia, gerentes e supervisores de marketing, ou seja, profissionais envolvidos com a tomada de decisão em portfólio de produtos e com a operacionalização o PDP.

Obteve-se 40 questionários válidos para a finalidade proposta neste artigo. Os resultados foram compilados e analisados por meio de estatística descritiva. Compararam-se também os resultados para a tomada de decisão em portfólio de produtos considerando o porte das empresas, ou seja, também foram observadas as diferenças de métodos aplicados entre as empresas de médio e de grande porte. $\mathrm{O}$ próximo tópico deste artigo apresenta e discute os resultados obtidos.

O próximo tópico inicialmente caracteriza a amostra e, em seguida os resultados obtidos são apresentados e analisados. 


\section{APRESENTAÇÃO DE RESULTADOS E DISCUSSÃO}

No que se refere à caracterização das empresas, conforme demonstra a tabela 1, a maioria delas é de médio porte (de 100 a 499 funcionários), uma vez que compõem aproximadamente $73 \%$ da amostra coletada.

Tabela 1 - Distribuição das empresas quanto ao porte.

\begin{tabular}{ccc}
\hline Porte & $\begin{array}{c}\mathbf{N}^{\circ} \text { de } \\
\text { Empresas }\end{array}$ & $\%$ \\
\hline Médio & 29 & 72,5 \\
Grande & 11 & 27,5 \\
\hline
\end{tabular}

A tabela 2 apresenta o principal método que as empresas adotam para a tomada de decisão em portfólio de produtos. É possível notar, que a maioria delas baseia-se, sobretudo, nas decisões informais e intuitivas da alta administração para esta deliberação - quase metade da amostra utiliza este mecanismo (48\%). Os mecanismos formais para a tomada de decisão, representados pelos diferentes métodos de gestão apresentados ao longo da revisão bibliográfica, são adotados pela outra metade das empresas pesquisadas (52\%).

Tabela 2 - Principal método adotado para a tomada de decisão em portfólio de produtos

\begin{tabular}{ccc}
\hline $\begin{array}{c}\text { Principal método para a } \\
\text { tomada de decisão em } \\
\text { portfólio }\end{array}$ & Número de Empresas & $\%$ \\
\hline $\begin{array}{c}\text { Decisão da alta } \\
\text { administração (não há um }\end{array}$ & 19 & 47,5 \\
método formal associado) & & \\
Financeiro & 8 & 20 \\
Pesquisa de mercado & 4 & 10 \\
Technology Roadmap & 3 & 7,5 \\
Mapas de Produtos & 2 & 5 \\
$\quad$ Pontuação & 2 & 5 \\
Checklist & 1 & 2,5 \\
Uso de diagramas (bolhas, & 1 & 2,5 \\
matriz BGC e GE) & &
\end{tabular}


A figura 1 permite a visualização desses mesmos resultados, a partir dos quatro mecanismos mais citados para a tomada de decisão em portfólio de produtos. Considerando que a aplicação de mapas de produtos e o technology roadmap são métodos que possuem a finalidade semelhante de planejamento no que se refere a gestão de portfólio de produtos, eles foram agrupados para análise apresentada nesta figura.

Figura 1 - Principais métodos adotados para a gestão de portfólio de produtos.
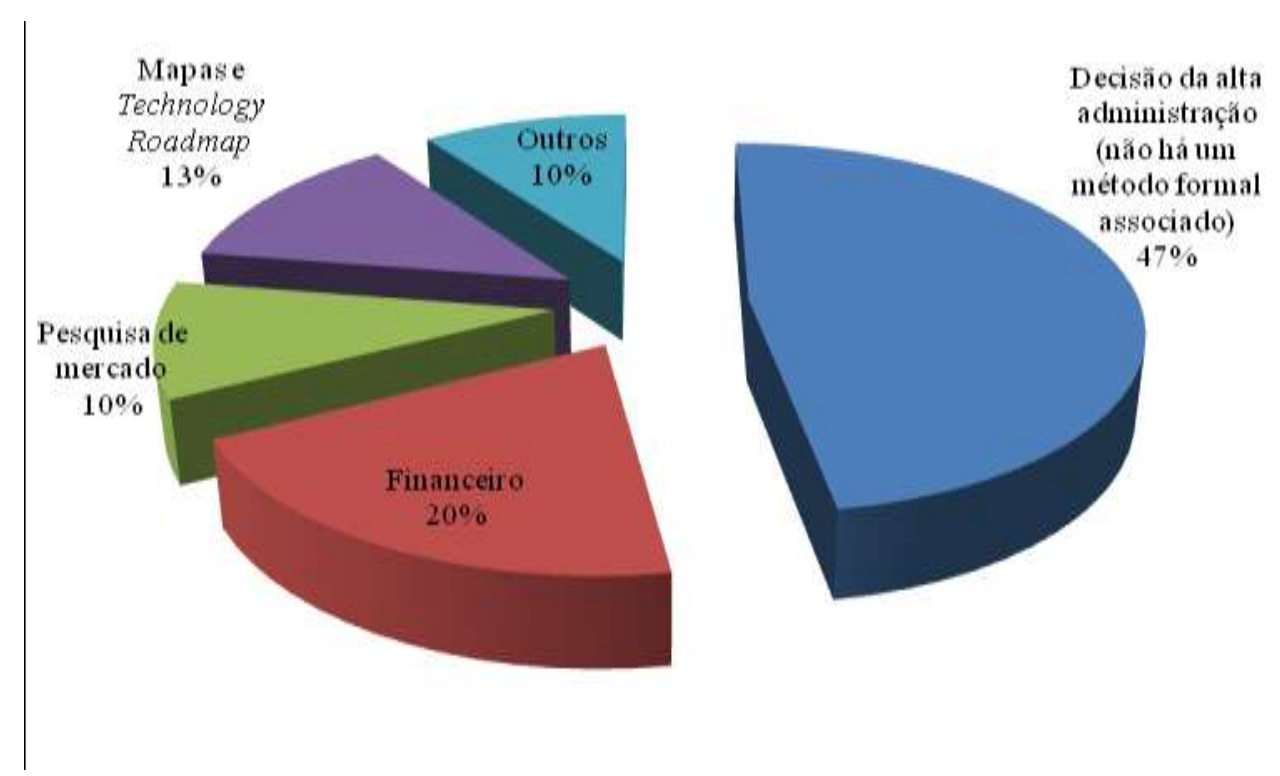

Ao se observar os resultados apresentados na tabela 1 e figura 1, é possível notar que a aplicação dos mecanismos formais e das práticas normalmente recomendadas pela literatura para a tomada de decisão em portfólio de produtos não são amplamente aplicadas pelas empresas da amostra, visto que cerca de metade delas guiam-se, sobretudo, pela decisões da alta administração para o encaminhamento dessas deliberações. Ou seja, a aplicação de métodos formais não é prioridade para a tomada de decisão em portfólio de produtos para grande parte das empresas pesquisadas. Este resultado converge com os resultados de algumas pesquisas internacionais e recentes, que demonstram que a tomada de decisão em portfólio de produtos também deve ser analisada a partir de mecanismos informais, subjetivos e de influência nas organizações (WEISSENBERGER-EIBL AND TEUFEL, 2011; MARTINSUO, 2013). 
No entanto, conforme apontam diversas pesquisas sobre o tema, com a pouca aplicação dos métodos formais para a gestão de portfólio de produtos e consequente menor quantidade de informações que possam subsidiar a tomada de decisão em projetos de produtos, aumenta-se a probabilidade de deliberações equivocadas no que se refere a quais produtos devem ser desenvolvidos, mantidos e descontinuados (COULON et al. 2009; KILLEN et al. 2008; KESTER et al. 2011; $\mathrm{OH}$ et al. 2012), fato que pode prejudicar o desempenho da gestão do portfólio de produtos e do PDP.

Como a amostra desta pesquisa foi constituída de empresas de médio e grande porte e que renovam seu portfólio de produtos de maneira frequente, havia a expectativa de presença de maior formalização e aplicação desses métodos de gestão para a tomada de decisão sobre quais produtos devem ser mantidos, desenvolvidos e descontinuados.

Também ao se examinar a figura 1, observa-se que dentre os métodos formais utilizados para a tomada de decisão em portfólio de produtos se destacam o financeiro, os mapas e a pesquisa de mercado. Ao se comparar esses resultados com pesquisas internacionais a respeito do tema, é possível observar divergências com o que os trabalhos de Cooper et al. (2000) e Killen (2008) observaram em empresas norte americanas, canadenses e australianas. Esses autores verificaram que os métodos financeiros, constituem-se nos principais mecanismos que as empresas utilizam para a tomada de decisão em portfólio de produtos. Notou-se, no caso brasileiro aqui investigado, que os mecanismos financeiros são adotados como principal meio para a tomada de decisão por $20 \%$ da amostra pesquisada, isto é, o segundo mecanismo mais citado.

As informações provenientes de pesquisa de mercado e necessidades de clientes foram indicadas como principal método para a tomada decisão por $10 \%$ das empresas pesquisadas. Além da importância básica do papel da pesquisa de mercado em se conhecer e captar necessidades de clientes para o desenvolvimento de novos produtos; outra provável razão para este resultado pode estar relacionada com mercado em que essas empresas atuam. Como muitas atuam no negócio de business-to-business, grande parte de seus projetos de novos produtos apenas são efetivamente iniciados quando efetivamente demandado pelos clientes. 
O uso dos mapas de produtos e a aplicação do technology roadmap como principal meio para a tomada de decisão em portfólio de produtos por $13 \%$ das empresas é resultado que também merece destaque. Afinal, são recentes os estudos no Brasil que mencionam a aplicação dos métodos de mapeamento como forma para se prever e gerenciar o portfólio de produtos e de tecnologias (Oliveira et al., 2012). Por outro lado, notou-se que as empresas não priorizam métodos tradicionalmente recomendados para a tomada de decisão em portfólio, como os checklist e diagramas; visto que apenas $10 \%$ delas mencionaram a aplicação desses métodos como principal meio para a tomada de decisão de portfólio, ou seja, quatro empresas.

A tabela 3 apresenta a frequência de aplicação desses métodos pesquisados, considerando o porte das empresas.

Tabela 3 - Principal método adotado para a tomada de decisão em portfólio de produtos considerando o porte das empresas

Porte da Empresa

Método Grande Médio

\begin{tabular}{ccc}
\hline $\begin{array}{c}\text { Decisão da alta } \\
\text { administração (não há um } \\
\text { método formal associado) } \\
\text { Financeiro }\end{array}$ & $27,2 \%$ & $55,2 \%$ \\
$\begin{array}{c}\text { Pesquisa de mercado e } \\
\text { necessidade de clientes } \\
\text { Mapas de Produtos e } \\
\text { Technology Roadmap }\end{array}$ & $36,4 \%$ & $13,8 \%$ \\
Pontuação & $9.1 \%$ & $10,3 \%$ \\
Checklist & $18,2 \%$ & $10,3 \%$ \\
Diagramas e Matrizes & $-1.1 \%$ & $3,5 \%$ \\
TOTAL & - & $3,5 \%$ \\
\end{tabular}

Ao se analisar a tabela 3, é possível notar que as empresas de grande porte possuem a gestão do portfólio de produtos mais formalizada em relação às de médio porte. Isto é evidenciado ao se observar que enquanto as decisões informais da alta 
administração constituem-se como o principal mecanismo para a tomada de decisão em portfólio de produtos para $55 \%$ das empresas de médio porte, apenas $27 \%$ das grandes empresas assinalaram esta opção. Devido a esta maior formalização, notase que é maior maturidade das empresas de grande porte no que se refere gestão de portfólio de produtos. De certa forma, este resultado já era esperado, uma vez que normalmente as empresas maiores possuem estruturas organizacionais bem consolidadas e dedicadas exclusivamente para lidar com aspectos de gestão.

Observa-se também na tabela 3 , que os métodos financeiros, prevalecem como principal mecanismo adotado pelas empresas de grande porte para a tomada de decisão em portfólio de produtos, utilizado por 36\% da amostra. Este resultado, por sua vez, converge com os resultados de pesquisas internacionais a respeito do tema que destacam a aplicação dos meios financeiros como meios preponderantes para a tomada de decisão em portfólio. Vale observar, nesse sentido, que há diferença significativa entre as grandes e as empresas de médio porte neste aspecto, uma vez que apenas $14 \%$ das empresas de médio porte utilizam os mecanismos financeiros como principal meio para a tomada de decisão em portfólio de produtos.

No que se refere à aplicação dos métodos formais para a tomada de decisão em portfólio de produtos, observa-se que nas empresas de grande porte, além do uso dos métodos financeiros, há concentração do emprego dos seguintes mecanismos: mapeamento e de pontuação. Surpreende neste caso, que apenas uma das empresas de grande porte mencionou que a pesquisa de mercado se constitui como principal mecanismo para a tomada de decisão em portfólio de produtos.

Diferentemente do padrão encontrado nas grandes empresas, as de médio porte se destacam pela maior informalidade na tomada de decisão em portfólio de produtos. Ao se analisar a tabela 3 é possível notar que cerca de $55 \%$ delas se caracterizam pela informalidade na tomada de decisão em portfólio de produtos, sendo predominantemente baseada da percepção da alta administração. Por serem empresas que atuam em ambientes inovadores e envolvidas em atividades continuas de desenvolvimento de novos produtos, havia a expectativa de que as médias empresas apresentassem um padrão mais formal para esta tomada de decisão.

Revista Produção Online, Florianópolis, SC, v.14, n. 3, p. 1151-1170, jul./set. 2014. 
Os resultados aqui apresentados demonstram a importância na maior divulgação e implantação dos seguintes métodos de gestão vinculados à gestão de portfólio e que possuem atualmente baixa aplicação pelas empresas: (I) os modelos de pontuação e priorização que permitem que os projetos de produtos sejam pontuados pela equipe envolvida com a gestão de portfólio, ranqueados e priorizados de acordo com a sua média esperada de performance; e (II) a adoção de gráficos e diagramas, como os de bolhas e as matrizes BCG e GE que são mecanismos úteis para simultaneamente se analisar o alinhamento entre portfólio de produtos com a estratégia da empresa e o balanceamento.

\section{CONCLUSÕES}

Por fazer parte da estratégia de inovação das empresas, definindo não somente produtos a serem desenvolvidos, lançados e descontinuados, mas, também, a alocação de recursos entre os diferentes departamentos envolvidos com o PDP, o conhecimento e a aplicação de métodos de gestão de portfólio de produtos é aspecto relevante para empresas envolvidas com as atividades de desenvolvimento de produtos.

A partir de uma pesquisa quantitativa, operacionalizada por meio de survey, este trabalho contribui com a áreas de conhecimento em gestão da inovação, do PDP e de projetos ao levantar e analisar os principais métodos que empresas de médio e grande porte dos setores eletrônico, óptico e de informática utilizam para a tomada de decisão em portfólio de produtos. Foi possível observar que as decisões informais da alta administração se consolidaram como o principal mecanismo para esta tomada de decisão, uma vez que cerca de metade das empresas pesquisadas mencionaram seguir este padrão. Nota-se, desta maneira, que aspectos políticos, de liderança e de barganha influenciam fortemente a tomada de decisão em portfólio de produtos nas empresas pertencentes aos setores pesquisados.

Esses resultados aqui apresentados convergem com algumas pesquisas internacionais e recentes que veem analisando esses aspectos na gestão de portfólio de projetos. Entende-se, assim, que estudos futuros poderiam analisar de maneira mais profunda como esses aspectos políticos e de liderança em empresas 
que atuam no Brasil influenciam a tomada de decisão no desenvolvimento de novos produtos.

Dentre os métodos formais mais citados, destaca-se a presença dos financeiros, de pesquisa de mercado e de mapeamento. Por serem bem disseminados e conhecidos tano no ambiente acadêmico quanto no empresarial, havia a expectativa de que a presença dos métodos financeiros, como valor presente líquido, taxa interna de retorno e payback, por exemplo, realmente teriam destaque neste trabalho. Sabe-se, que por outro lado, que aplicação única dos métodos financeiros tradicionais pode ser arriscada para a tomada de decisão em portfólio de produtos. Isso porque, este tipo de avaliação pode não conseguir realizar exatas previsões de demanda e, tampouco, mensurar de maneira adequada o impacto de determinada inovação tecnológica de produto. Neste sentido, entende-se que a aplicação dos métodos financeiros deve ser aplicada de maneira integrada com os demais métodos apresentados ao longo deste artigo. Além disso, no tocante a aplicação dos métodos financeiros, a análise da teoria das opções reais aplicada a portfólio de produtos pode representar um interessante campo de pesquisas futuras, especialmente quando o foco de estudo forem empresas de base tecnológica.

Devido ao seu caráter recente em termos de pesquisa e publicações em empresas que atuam no país, surpreende a quantidade de empresas que utilizam o mecanismo de mapeamento como principal método para a tomada de decisão em portfólio de produtos. Pesquisas qualitativas futuras, sob a forma de estudos de casos, também poderiam identificar as motivações e práticas específicas de mapeamento que empresas têm empregado em sua gestão de portfólio de produtos.

Espera-se que os resultados desta pesquisa possam somar-se ao corpo de conhecimento em gestão de portfólio de produtos em empresas que atuam no país. Destaca-se que este trabalho apenas identificou apenas o principal método de gestão que empresas utilizam para a tomada de decisão em portfólio de produtos, porém, não foi mensurado o grau de importância que as empresas conferem a cada um deles. Além disso, o estudo foi feito em empresas de médio e grande porte dos setores eletrônicos, ópticos e equipamentos de informática. Trabalhos futuros poderiam ampliar os resultados desta pesquisa, de modo a identificar os principais métodos para a tomada de decisão em portfólio de produtos que são adotados por empresas pertencentes a outros setores da economia. Por fim, pesquisas futuras Revista Produção Online, Florianópolis, SC, v.14, n. 3, p. 1151-1170, jul./set. 2014. 
poderiam também correlacionar a aplicação dos diferentes métodos e práticas recomendadas para a gestão em portfólio de produtos com o próprio desempenho da gestão do portfólio e com os resultados obtidos com os novos produtos.

\section{AGRADECIMENTOS}

Os autores agradecem a FAPESP pelo apoio financeiro concedido (processo $11 / 51596-5)$.

\section{REFERÊNCIAS}

ARCHER, N. P.; GHASEMZADEH, F. An integrated framework for project portfolio selection, International Journal of Project Management, v.17, n. 4, p.207-216, 1999. http://dx.doi.org/10.1016/S0263-7863(98)00032-5

BARROS, L. A.; SANCHES DA SILVA, C. E.; MELLO, C. H. P. Identificação de fatores para a implementação de técnicas de gestão de portfólio de projetos: estudo de caso em uma empresa global do setor químico. Revista Produção Online, vol.10, n. 2, p. 224-249.

CASTRO, H. G.; CARVALHO, M. M. Gerenciamento de portfólio: um estudo exploratório, Gestão \& Produção, v. 17, n. 2, p. 283-296, 2010.

http://dx.doi.org/10.1590/S0104-530X2010000200006

CAUCHICK MIGUEL, P. A. Implementação da gestão de portfólio de novos produtos: um estudo de caso. Revista Produção, v. 18, n. 2, p. 388-404, 2008.

CHENG, L. C. QFD em desenvolvimento de produto: características metodológicas e um guia para a intervenção. Revista Produção Online, vol.3, n. 2, p. 627.

CHRISTIANSEN, J. K.; VARNES, C.. From models to practice: decisions making at portfolio meetings. International Journal of Quality \& Reliability Management, vol. 25, n. 1, p. 87-101, 2008. http://dx.doi.org/10.1108/02656710810843603

COOPER, R. G.; EDGETT, S. J.; KLEINSCHMIDT, E. J. New problems, new solutions: making portfolio management more effective. Research Technology Management, v. 43, n.2, p. 18-33, 2000. http://dx.doi.org/10.1016/S0737-6782(99)00005-3

COOPER, R. G.; EDGETT, S. J.; KLEINSCHMIDT, E, J. New product portfolio management: practices and performance. Journal of Product Innovation Management, v. 16, n.4, p. 331-351, 1999.

COULON, M.; ERNST, H.; LICHTENTGALER, U.; VOLLMOELLER, J. An overview of tools for managing the corporate innovation portfolio. International Journal of 
Technology Intelligence and Planning, vol 5, n.2, p. 221-239, 2009. http://dx.doi.org/10.1504/IJTIP.2009.024191

CUNHA, V. P.; OLIVEIRA, M. C.; ROZENFELD, H. Planejamento da inovação: análise e identificação das suas principais fases. Revista Produção Online, vol. 13, n.2, p. 737-758, 2010. http://dx.doi.org/10.14488/1676-1901.v13i2.1335

EGGERS, J. P. All experience is not created equal: learning, adapting, and focusing in product portfolio management. Strategic Management Journal, vol. 33, n. 3 p. 315-335, 2012. http://dx.doi.org/10.1002/smj.956

ERNST, H. Success factors of new products development: a review of the empirical literature. International Journal of Management Reviews, v. 4, n. 1, p. 1-40, 2002. http://dx.doi.org/10.1111/1468-2370.00075

KAHN, K. B.; BARCZAK, G.; MOSS, R. Perspective: establishing an NPD best practices framework. The Journal of product innovation management, v. 23, p. 106-116, 2006. http://dx.doi.org/10.1111/j.1540-5885.2006.00186.x

FORZA, C. Survey research in operations management: a process-based perspective. International Journal of Operations \& Product Management, v.22, n. 2, p. 105-112, 2002. http://dx.doi.org/10.1108/01443570210414310

HAUSER, J., TELLIS, G. J., GRIFFIN, A. Research on innovation and new products: a review agenda for marketing science. Marketing Science, vol. 25, n.6, p.687-717, 2006. http://dx.doi.org/10.1287/mksc.1050.0144

IBGE. PINTEC - Pesquisa Nacional Tecnológica, Rio de Janeiro, 2010.

JUGEND, D.; SILVA, S. L. Inovação e desenvolvimento de produtos: práticas de gestão e casos brasileiros. Rio de Janeiro: LTC, 2013.

JUGEND, D. SILVA, S. L. Práticas de gestão que influenciam o sucesso de novos produtos em empresas de base tecnológica. Revista Produção, v. 20, n. 3, p. 335346, 2010. http://dx.doi.org/10.1590/S0103-65132010005000041

KAVADIAS, S.; CHAO, R.O. Resource allocation and new product portfolio management. In: LOCH, C.H.; KAVADIAS, S. (eds.) Handbook of research in new product development management. Butterworth/Heinemann (Elsevier), Oxford UK, p.135-163, 2007.

KESTER, L., GRIFFIN, A., HULTINK, E.J., LAUCHE, K., 2011. Exploring portfolio decision-making process. Journal of Product Innovation Management, v. 28, n.5, p. 641-661, 2011. 
KILLEN, C. P.; KJAER, C. Evaluation of project interdependency visualizations through decision scenario experimentation. International Journal of Project

Mananagement, v. 31, n.6, p. 804-813, 2013.

http://dx.doi.org/10.1016/j.ijproman.2012.09.005

KILLEN, C. P.; HUNT, R. A.; KLEINSCHMIDT, E.J., Project portfolio management for product innovation. International Journal of Quality \& Reliability Management, vol. 25, n.1, p24-38, 2008. http://dx.doi.org/10.1108/02656710810843559

KOEN, P. A.; AJAMIAN, G. M.; BOYCE, S.; CLAMEN, A.; FISHER, E.; FOUNTOULAKIS, S.; JOHNSON, A.; PURL, P.; SEIBERT, R. Fuzzy front end: effective methods, tools, and techniques. In: BELLIVEAN, P., GRIFFIN, A., SOMERMEYER, S. (edts), The PDMA handbook of new product development. John Wiley \& Sons, New Jersey, p. 1-35, 2002.

MARTINSUO, M. Project portfolio management in practice and in context. International Journal of Project Management, vol. 31, n. 6, p. 794-803, 2013. http://dx.doi.org/10.1016/j.ijproman.2012.10.013

MATHEWS, S. Innovation portfolio architecture - part 2: attribute selection and valuation. Research Technology Management, vol 54, n.5, p. 37-47, 2011. http://dx.doi.org/10.5437/08956308X5405005

McNALLY, R. C.; DURMUŞOĞLU, S. S.; CALANTONE, R. J. New product portfolio management decisions: antecedents and consequences. Journal of Product Innovation Management, v. 30, n. 2, p. 245-261, 2013.

http://dx.doi.org/10.1111/j.1540-5885.2012.00997.x

McNALLY, R.C.; DURMUSOGLU, S.S.; CALANTONE, R.J.; HARMANCIOGLU, N. Exploring new product portfolio management decisions: the role of managers' dispositional traits. Industrial Marketing Management, v. 38, n.1, p.127-143, 2009. http://dx.doi.org/10.1016/j.indmarman.2007.09.006

MIGUEL, P. A. C.; HO, L. L. Levantamento tipo survey. In: MIGUEL, P. A. C. (Org.) Metodologia de pesquisa em engenharia de produção e gestão de operações. Rio de Janeiro: Elsevier, p. 73-128, 2010.

MIKKOLA, J. M. Portfolio management of R\&D projects: implications for innovation management. Technovation, vol.21, n. 7, p. 423-435, 2001.

http://dx.doi.org/10.1016/S0166-4972(00)00062-6

MOREIRA, R. A.; CHENG. L. C. Proposal of managerial standards for new product portfolio management in Brazilian pharmaceutical companies. Brazilian Journal of Pharmaceutical Sciences, vol. 46, n. 1, p. 53-66, 2010.

http://dx.doi.org/10.1590/S1984-82502010000100007 
$\mathrm{OH}$, J.; YANG, J.; LEE, S. Managing uncertainty to improve decision-making in NPD portfolio management with a fuzzy expert system. Expert System with Application , vol. 39, n. 10, p. 9868-9885, 2011. http://dx.doi.org/10.1016/j.eswa.2012.02.164

OLIVEIRA, M. G., FREITAS, J. S.; FLEURY, A. L.; ROZENFELD, H.; PHAAL, R.; PROBERT, D.; CHENG, L. C. Roadmapping: uma abordagem estratégica para o gerenciamento da inovação em produtos, serviços e tecnologias, Rio de Janeiro: Elsevier, 2012.

OLIVEIRA, M.G.; ROZENFELD, H. Integrating technology roadmapping and portfólio management at the front-end of new product development. Technological

Forecasting \&Social Change, vol. 77, n. 8, p. 1339-1354, 2010.

http://dx.doi.org/10.1016/j.eswa.2012.02.164

PADOVANI, M.; CARVALHO, M. M.; MUSCAT, A. R. N. Ajuste e balanceamento do portfólio de projetos: o caso de uma empresa do setor químico. Revista Produção, v. 22, n. 4, p. 651-673, 2012. http://dx.doi.org/10.1590/S0103-65132012005000064

PHAAL, R.; FARRUKH, C.; PROBERT, D. T Plan: Fast Start to Technology Roadmapping: planning your route to success. University of Cambridge, Institute for Manufacturing, 2001.

PHAAL, R.; SIMONSE, L.; OUDEN, E. D. Next generation roadmapping for innovation planning, International Journal of Technology Intelligence and Planning, vol. 4 n.0.2, p.135-152, 2008.

PEDROSO, C.; PAULA, I. C.; SOUZA, J. S. Análise comparativa de ferramentas de gestão de portfólio: um estudo de caso na indústria alimentícia. Revista Produção, v.22, n. 4, p. 637-650, 2012. http://dx.doi.org/10.1590/S0103-65132012005000078

ROZENFELD, H.; FORCELLINI, F. A.; AMARAL, D. C.; TOLEDO, J. C.; SILVA, S. L.; ALLIPRANDINI, D. H.; SCALICE, R.; K. Gestão de desenvolvimento de produto: uma referência para a melhoria do processo. São Paulo: Saraiva, 2006.

SANTOS, E. M.; PAMPLONA, E. O. Teoria das Opções Reais: uma atraente opção no processo de análise de investimentos. Revista da Administração, v.40, n.3, p.235-252, 2005.

SOUDER, W. E.; BUISSON, D.; GARRET, T. Success through customer-driven new product development: a comparison of US and New Zealand small entrepreneurial high technology firms. Journal of Product Innovation Management, vol. 14, n.5, p. 459-472, 1997. http://dx.doi.org/10.1016/S0737-6782(97)00064-7

TOLEDO, J. C.; SILVA, S. L.; MENDES, G. H. S.; JUGEND, D. Fatores críticos de sucesso no gerenciamento de projetos de desenvolvimento de produto em empresas de base tecnológica de pequeno e médio porte. Gestão \& Produção, São Carlos, v. 15, n. 1, p. 117-134, 2008. 
VERMULUM, R.; ERBER, F. Cadeia: bens de capital, working paper, Universidade de Campinas - Finep, Campinas, 2002.

WEISSENBERGER-EIBL, M. A.; TEUFEL, B. Organizational politics in new product development project selection: a review of the current literature. European Journal of Innovation Management, v. 14, n. 1, p.51-73, 2011.

http://dx.doi.org/10.1108/14601061111104698

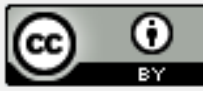

Artigo recebido em 20/11/2013 e aceito para publicação em 15/04/2014

DOI: http://dx.doi.org/ 10.14488/1676-1901.v14i3.1704

Revista Produção Online, Florianópolis, SC, v.14, n. 3, p. 1151-1170, jul./set. 2014. 